\title{
Reactions in the Annual Medicago Core Germ Plasm Collection to Two Isolates of Peronospora trifoliorum from Alfalfa
}

\author{
J. R. Yaege and D. L. Stuteville, Department of Plant Pathology, Throckmorton Plant Sciences Center, Kansas \\ State University, Manhattan, KS 66506-5502
}

\begin{abstract}
Yaege, J. R., and Stuteville, D. L. 2000. Reactions in the annual Medicago core germ plasm collection to two isolates of Peronospora trifoliorum from alfalfa. Plant Dis. 84:521-524.

Peronospora trifoliorum causes downy mildew of alfalfa throughout the temperate regions of the world, but little is known about its host range within the annual Medicago species (medics). Several medics have characteristics potentially beneficial to sustainable agriculture programs and to the genetic improvement of alfalfa. Therefore, we evaluated resistance in 199 accessions representing 33 species of the annual Medicago core germ plasm collection to $P$. trifoliorum isolates I7 and I8 from alfalfa from Kansas and southern California, respectively. Seedlings at the cotyledonary growth stage were inoculated with conidia suspended in water. One week later, the plants were rated resistant (no conidium production) or susceptible (conidium production). High levels of resistance existed in all species. All plants in $142(71 \%)$ of the accessions were resistant to both isolates, but plants in only 24 of those resistant accessions were free of chlorotic to necrotic hypersensitive reactions on the inoculated cotyledons. All but one of the medic accessions had a higher percentage of plants resistant to both isolates than did cv. Saranac alfalfa, the resistant control. Conidium production generally was much less intense on the susceptible medic plants than on the alfalfa controls. A greater percentage of plants in four medic accessions was more resistant to I8 than to I7, and 22 were more resistant to I7 than to I8.
\end{abstract}

Annual species of the genus Medicago, commonly known as annual medics or medics, evolved from the perennial Medicago species in the Mediterranean region (5,7). Medics self-pollinate, self-seed, and host nitrogen-fixing bacteria. In nature, the herbaceous medics, except M. lupulina L., complete their life cycle from seed germination to plant death within one growing season (5). Medics have long been utilized in the regions of Australia (1) and South Africa (3) that have a Mediterranean climate. Medics have received increased attention in the United States as cover crops, companion crops, and pasture legumes, particularly in sustainable agriculture programs. Traits within the medics that are potentially useful to improve alfalfa include drought tolerance, glandular hairs for natural resistance to insects, and larger seeds to aid seeding and enhance seedling vigor (5).

Because of their close genetic relationship, annual medics and alfalfa (Medicago sativa L.) share many common diseases $(3,8,12)$. Downy mildew, caused by Pero-

Corresponding author: D. L. Stuteville

E-mail: dls@plantpath.ksu.edu

This is contribution number 99-344-J from the Kansas Agricultural Experiment Station.

Accepted for publication 25 December 1999.

Publication no. D-2000-0228-02R

(c) 2000 The American Phytopathological Society nospora trifoliorum de Bary, occurs on alfalfa throughout the United States and in all temperate regions of the world (10). All 631 alfalfa plant introduction (PI) accessions from 50 countries previously evaluated included plants susceptible to pathogenically distinct $P$. trifoliorum isolate I7 from Kansas and isolate I8 from southern California $(4,9)$. However, downy mildew has been reported in the United States on only one medic, M. lupulina (6), which is not a true annual (5). No plants in single lots of five glandular-haired annual medic species evaluated supported conidial production by isolate I7 or I8 (12).

The annual Medicago core collection, comprising 211 accessions from 36 species, was developed to represent the genetic variability in the United States National Plant Germplasm System's medic collection of over 3,000 accessions (2). This investigation was initiated to evaluate the reaction of the annual Medicago core collection to $P$. trifoliorum isolates I7 and I8 from alfalfa.

\section{MATERIALS AND METHODS}

Seeds of 199 available accessions representing 33 species in the annual Medicago core collection (2) were obtained from the USDA Western Regional Plant Introduction Station, 59 Johnson Hall, Pullman, Washington. At least 18 seeds were planted per $7.5 \mathrm{~cm}^{2}$ pot of steam-sterilized fine sand. The seeding rate was adjusted to compensate partially for germinability differences among seed lots. One pot each of 30 randomly selected medic accessions and the control alfalfa cultivars, Kanza (susceptible) and Saranac (resistant) (11), was seeded and inoculated each week.

Conidia of $P$. trifoliorum isolates I7 and I8 used for inoculum were produced on Kanza alfalfa. Inoculum production and inoculation procedures used were as described for alfalfa $(9,11)$. However, to compensate for differences in emergence rates among the medics, planting dates were adjusted so that all plants in a test were inoculated at the cotyledonary stage of growth. Inoculum consisted of at least 25,000 conidia per milliliter of water and was sprayed onto plants until a drop formed between the cotyledons of each plant.

The weekly plantings of 30 accessions plus controls were continued until all accessions were tested. The process was repeated with each isolate until all accessions were included in three replications. For accessions with very low seed viability, the replications were continued until at least 50 plants of each accession were evaluated for each isolate. At that time, to conserve seed, testing was stopped on accessions having no plants supporting conidium production. However, accessions with plants that supported conidium production were included in additional replications until at least 100 plants were evaluated for each isolate. The plants not supporting conidium production were considered resistant. This differs from the alfalfa standard test (11), in which only the plants free of signs and symptoms are considered resistant, and thus plants with hypersensitive reactions were considered susceptible. This change was made to compensate for resistance due to hypersensitive reactions, which were much more common on the medics than on alfalfa.

Conidium production was verified by examining plants at $\times 25$ magnification with a binocular dissecting microscope. The accessions with all plants resistant to both isolates were assigned a numerical scale for symptoms resulting from chlorotic to necrotic hypersensitive reactions on the cotyledons. The scale used was: $0=$ no symptoms, $1=$ symptoms on $<25 \%$ of plants, $2=$ symptoms on 25 to $75 \%$ of plants, and $3=$ symptoms on $>75 \%$ of plants.

An alpha level of 0.05 was used for all statistical tests. Standard errors for mean percent resistance were based on the bino- 
mial distribution. Significant differences in mean percent resistance by isolate were determined by a $\mathrm{Z}$ test.

\section{RESULTS}

Of the 199 accessions evaluated, 142 supported no conidium production by either $P$. trifoliorum isolate (Table 1). These included all accessions of $M$. ciliaris, $M$. constricta, $M$. coronata, $M$. disciformis, $M$. granadensis, $M$. intertexta, $M$. italica, $M$. laciniata, M. lesinsii, M. minima, M. muricoleptis, M. orbicularis, M. praecox, and $M$. rigidula. Within the 142 resistant accessions, 45 and 46 supported no symptoms to isolates I7 and I8, respectively, and 24 supported no symptoms to both isolates. The remaining accessions in Table 1 included plants in which a hypersensitive response on the inoculated cotyledons produced symptoms ranging from a light chlorotic or necrotic stipple to a rapid death of the cotyledons. As the proportion of plants with symptoms increased within an accession (Table 1), the severity of symptoms on the individual plants within that accession also tended to increase. Thus, symptoms were most severe on some M. laciniata accessions and resulted in the death of cotyledons on affected plants (Table 1). Later stages of growth never expressed the chlorotic or necrotic symptoms, although the early death of cotyledons usually retarded seedling growth.

The remaining 57 accessions included plants that supported conidium production by I7 and/or I8 (Table 2). These included all 24 accessions representing $M$. arabica, $M$. blancheana, M. heyniana, M. lanigera, $M$. radiata, $M$. rotata, $M$. sauvagei, and $M$. tenoreana. Eleven of the 57 accessions included plants susceptible to only one isolate; all plants in eight accessions were resistant to I8, and all plants in three accessions were resistant to I7. However, significantly $(P=0.05)$ more plants in 22 accessions were resistant to I7 than to I8, whereas plants in only four accessions were more resistant to I8 than to I7. The lowest percentage of plants resistant to I8 was 25.5 in M. blancheana PI 495223, and the lowest percent resistant to I7 was 60.4 in M. radiata PI 495146 (Table 2).

Eleven species included a portion of accessions with all plants resistant to both isolates (Table 1) and also included accessions with plants susceptible to I7 and/or I8 (Table 2). These species and the numbers of accessions within each listed in Tables 1 and 2, respectively, were $M$. doliata 3,1; M. littoralis 6,$1 ;$ M. lupulina 4,12; M. murex 4,$2 ; M$. noeana 1,$1 ; M$. polymorpha 21,2; M. rugosa 5,6; M. scutellata 13,4; . soleirolii 1,$1 ; M$. truncatula 7,2 ; and $M$. turbinata 3,1.

Seedlings in accessions with sporulation (Table 2) also expressed the range of symptoms described in Table 1. For example, about $70 \%$ of $M$. noeana PI 495414 seedlings were resistant to I7 and I8 (Table 2), but about $90 \%$ of them reacted to both isolates with a whitish chlorotic stipple on the inoculated cotyledons. The most severely affected of those plants died prior to conidium production. However, when the inoculation of this accession was delayed 1 to 2 days, symptoms on the cotyledons were less severe, and the proportion of plants supporting conidium production increased.

Reaction by M. tenoreana PI 499161 to both isolates was unusual, in that the cotyledons had few symptoms and no conidia, but the unifoliolate leaves of infected plants supported conidium production.

Resistance to isolates I7 and I8 was much greater in most annual medic accessions than in Saranac alfalfa, the resistant control (Table 2), and conidium production was less intense on most medics than on the infected alfalfa control plants.

\section{DISCUSSION}

P. trifoliorum isolates $\mathrm{I} 7$ and I8 from alfalfa infected plants of several medic species, but most medic accessions had much greater levels of resistance than reported for PI accessions of alfalfa (9). None of the 631 alfalfa accessions were free of symptoms for either isolate (9), whereas all plants in 24 of 199 (12\%) annual medic accessions tested were symptomless. An additional 59\% (118 of 199) of medic accessions included plants that developed hypersensitive reactions but did not support conidium production by either isolate. These hypersensitive reactions were much more common and more intense on medics

Table 1. Seedling reactions within Plant Introduction (PI) accessions of the annual Medicago core collection in which no plants supported conidium production by Peronospora trifoliorum isolates I7 and I8

\begin{tabular}{|c|c|c|c|c|c|c|c|c|c|c|c|c|c|c|c|c|c|}
\hline \multicolumn{3}{|c|}{ Species } & \multicolumn{3}{|c|}{ Species } & \multicolumn{3}{|l|}{ Species } & \multicolumn{3}{|l|}{ Species } & \multicolumn{3}{|c|}{ Species } & \multicolumn{3}{|c|}{ Species } \\
\hline PI & I7 & I8 & PI & I7 & I8 & PI & I7 & I8 & PI & I7 & I8 & PI & I7 & I8 & PI & I7 & I8 \\
\hline M. ciliaris & & & M. intertexta & & & 537259 & 1 & 1 & 251474 & 0 & 0 & 566873 & 0 & 1 & M. scutellata & & \\
\hline 368928 & $0^{\mathrm{a}}$ & & 498824 & 0 & 0 & M. littoralis & & & 283645 & 1 & 1 & 566874 & 1 & 1 & 161415 & 0 & 0 \\
\hline 442645 & 1 & 1 & 516649 & 1 & 0 & 385006 & 1 & 1 & 292421 & 0 & 1 & 566875 & 1 & 1 & 197806 & 0 & 1 \\
\hline 498731 & 0 & 0 & 516650 & 0 & 0 & 537168 & 0 & 1 & 505425 & 1 & 0 & 566876 & 1 & 1 & 197817 & 1 & 1 \\
\hline 498750 & 0 & 0 & 535606 & 0 & 0 & 537171 & 1 & 1 & 566870 & 0 & 0 & 566877 & 0 & 1 & 197821 & 1 & 1 \\
\hline 498784 & 0 & 0 & 535607 & 1 & 0 & 537201 & 1 & 1 & 566871 & 0 & 1 & 566878 & 0 & 1 & 292432 & 1 & 0 \\
\hline 498785 & 1 & 1 & M. italica & & & 537207 & 1 & 1 & 566872 & 1 & 1 & 566879 & 1 & 1 & 487393 & 0 & 0 \\
\hline M. constricta & & & 384640 & 1 & 1 & 537222 & 0 & 1 & M. polymorpha & & & 566880 & 0 & 0 & 487394 & 1 & 0 \\
\hline 495240 & 1 & 0 & 385014 & 1 & 1 & M. lupulina & & & 186329 & 1 & 1 & 566882 & 0 & 1 & 487396 & 1 & 1 \\
\hline 534177 & 1 & 1 & 459188 & 1 & 1 & 319026 & 1 & 2 & 197340 & 1 & 0 & 566883 & 1 & 1 & 487411 & 0 & 1 \\
\hline 534182 & 0 & 0 & 566864 & 1 & 0 & 452459 & 1 & 2 & 197530 & 1 & 0 & 566884 & 1 & 1 & 517255 & 1 & 0 \\
\hline M. coronata & & & 566865 & 1 & 1 & 532942 & 1 & 3 & 206695 & 1 & 0 & 566885 & 0 & 0 & 535643 & 1 & 1 \\
\hline 498790 & 1 & 1 & 566866 & 1 & 1 & 566869 & 2 & 1 & 226648 & 1 & 0 & M. praecox & & & 535644 & 0 & 1 \\
\hline 498805 & 1 & 1 & 566867 & 1 & 3 & M. minima & & & 244312 & 0 & 1 & 495429 & 0 & 0 & 535645 & 0 & 0 \\
\hline M. disciformis & & & 566868 & 2 & 1 & 227032 & 1 & 1 & 250782 & 0 & 0 & 495434 & 1 & 0 & M. soleirolii & & \\
\hline 487317 & 1 & 1 & M. laciniata & & & 499072 & 1 & 1 & 253448 & 1 & 0 & M. rigidula & & & 537242 & 1 & 1 \\
\hline 487321 & 1 & 0 & 498839 & 3 & 3 & 499080 & 1 & 2 & 286534 & 1 & 0 & 230350 & 0 & 1 & M. truncatula & & \\
\hline 487322 & 0 & 1 & 498841 & 3 & 3 & M. murex & & & 292427 & 1 & 1 & 233250 & 1 & 1 & 292436 & 1 & 1 \\
\hline 487333 & 1 & 1 & 498842 & 3 & 3 & 308062 & 1 & 1 & 302926 & 1 & 0 & 319048 & 1 & 1 & 384648 & 1 & 1 \\
\hline M. doliata & & & 498853 & 2 & 2 & 495350 & 1 & 1 & 308055 & 1 & 1 & 495517 & 1 & 1 & 566887 & 1 & 1 \\
\hline 505420 & 1 & 0 & 498864 & 1 & 1 & 516720 & 0 & 1 & 319036 & 1 & 1 & 534236 & 1 & 0 & 566888 & 1 & 1 \\
\hline 534202 & 1 & 0 & 498890 & 1 & 1 & 534231 & 1 & 0 & 368949 & 0 & 1 & 534250 & 0 & 1 & 566889 & 0 & 0 \\
\hline 534211 & 0 & 0 & 498902 & 1 & 2 & M. muricoleptis & & & 385017 & 0 & 0 & M. rugosa & & & 566891 & 2 & 1 \\
\hline M. granadensis & & & 498916 & 1 & 2 & 495401 & 0 & 0 & 404795 & 1 & 1 & 368962 & 1 & 1 & 566892 & 1 & 1 \\
\hline 498812 & 0 & 0 & 498918 & 2 & 2 & M. noeana & & & 459130 & 1 & 1 & 487377 & 1 & 1 & M. turbinata & & \\
\hline 498813 & 0 & 0 & 535738 & 1 & 1 & 495407 & 1 & 2 & 478531 & 1 & 1 & 487386 & 0 & 2 & 441943 & 1 & 1 \\
\hline 498817 & 1 & 0 & M. lesinsii & & & M. orbicularis & & & 493292 & 1 & 1 & 535534 & 2 & 1 & 535555 & 1 & 1 \\
\hline & & & 534233 & 0 & 0 & 210425 & 0 & 0 & 493293 & 0 & 1 & 535537 & 1 & 2 & 566893 & 0 & 1 \\
\hline
\end{tabular}

a Chlorotic to necrotic symptoms: $0=$ no symptoms, $1=$ symptoms on $<25 \%$ of the plants, $2=$ symptoms on 25 to $75 \%$ of plants, and $3=$ symptoms on $>75 \%$ of plants. 
than we have observed on alfalfa. Thus, the alfalfa standard test (11) was altered to provide resistance status to medic plants with hypersensitive symptoms and no sporulation. This change had little effect on the resistance evaluations for Kanza; approximately 8 and $1 \%$ of plants remained free of sporulation by $\mathrm{I} 7$ and I8, respec- tively (Table 2), compared with the 0 to $5 \%$ expected to be symptomless for each in the standard test (11). Likewise, the $61 \%$ of Saranac plants showing sporulation-free resistance to I8 (Table 2) was similar to the 50 to $60 \%$ expected to be symptomless (11). However, the $37 \%$ of Saranac plants showing sporulation-free resistance to $\mathrm{I} 7$

Table 2. Percentage of plants resistant to Peronospora trifoliorum isolates I7 and I8 within those annual Medicago core collection Plant Introduction (PI) accessions with plants susceptible to one or both isolates

\begin{tabular}{|c|c|c|c|}
\hline \multirow[b]{2}{*}{ Species } & \multirow[b]{2}{*}{ PI } & \multicolumn{2}{|c|}{ Resistant $(\%)^{\mathrm{a}}$} \\
\hline & & I7 & I8 \\
\hline \multirow[t]{2}{*}{ M. arabica } & $495200^{b}$ & $91.7 \pm 2.3$ & $80.8 \pm 3.3$ \\
\hline & 495212 & $93.5 \pm 2.4$ & $87.4 \pm 3.6$ \\
\hline \multirow[t]{7}{*}{ M. blancheana } & $495215^{b}$ & $88.0 \pm 3.4$ & $70.2 \pm 5.0$ \\
\hline & $495216^{b}$ & $100.0 \pm 0.0$ & $92.5 \pm 2.1$ \\
\hline & $495223^{b}$ & $68.0 \pm 2.6$ & $25.5 \pm 2.7$ \\
\hline & $495227^{b}$ & $98.4 \pm 1.1$ & $83.5 \pm 3.4$ \\
\hline & 505415 & $98.9 \pm 0.8$ & $96.9 \pm 1.4$ \\
\hline & $505416^{\mathrm{b}}$ & $99.0 \pm 1.0$ & $87.9 \pm 2.7$ \\
\hline & 537130 & $84.9 \pm 3.5$ & $78.2 \pm 3.5$ \\
\hline M. doliata & $495278^{b}$ & $98.2 \pm 1.3$ & $87.6 \pm 2.9$ \\
\hline M. heyniana & 537136 & $79.8 \pm 3.8$ & $85.7 \pm 3.1$ \\
\hline M. lanigera & $498930^{\mathrm{b}}$ & $100.0 \pm 0.0$ & $88.2 \pm 4.5$ \\
\hline M. littoralis & 517206 & $99.2 \pm 0.8$ & $96.3 \pm 1.6$ \\
\hline \multirow[t]{12}{*}{ M. lupulina } & 189128 & $91.7 \pm 2.3$ & $85.6 \pm 3.2$ \\
\hline & $202038^{b}$ & $100.0 \pm 0.0$ & $95.3 \pm 1.7$ \\
\hline & $215245^{b}$ & $96.9 \pm 1.5$ & $87.2 \pm 3.2$ \\
\hline & $223872^{b}$ & $78.9 \pm 4.3$ & $64.1 \pm 5.0$ \\
\hline & $227452^{\mathrm{b}}$ & $92.3 \pm 1.9$ & $86.5 \pm 2.6$ \\
\hline & $234821^{b}$ & $91.5 \pm 2.6$ & $58.0 \pm 4.0$ \\
\hline & $251834^{b}$ & $97.0 \pm 1.5$ & $85.1 \pm 2.9$ \\
\hline & 269926 & $92.5 \pm 2.4$ & $86.0 \pm 3.5$ \\
\hline & 290723 & $96.3 \pm 1.8$ & $97.0 \pm 1.3$ \\
\hline & 304527 & $95.6 \pm 1.8$ & $96.1 \pm 1.9$ \\
\hline & $308059^{b}$ & $83.2 \pm 3.2$ & $60.9 \pm 4.7$ \\
\hline & $314538^{\mathrm{b}}$ & $98.1 \pm 0.9$ & $84.5 \pm 2.7$ \\
\hline \multirow{2}{*}{ M. murex } & $495379^{b}$ & $99.3 \pm 0.7$ & $87.3 \pm 2.9$ \\
\hline & $566894^{b}$ & $97.3 \pm 1.5$ & $65.3 \pm 4.0$ \\
\hline M. noeana & 495414 & $71.4 \pm 2.7$ & $68.6 \pm 2.9$ \\
\hline \multirow{2}{*}{ M. polymorpha } & 283657 & $99.0 \pm 1.0$ & $98.9 \pm 1.1$ \\
\hline & 566881 & $98.7 \pm 1.3$ & $96.2 \pm 2.2$ \\
\hline \multirow[t]{4}{*}{ M. radiata } & $340800^{\mathrm{b}}$ & $86.0 \pm 3.1$ & $98.5 \pm 1.1$ \\
\hline & $459142^{b}$ & $91.5 \pm 2.5$ & $100.0 \pm 0.0$ \\
\hline & 459145 & $86.2 \pm 2.9$ & $89.8 \pm 2.5$ \\
\hline & $459146^{\mathrm{b}}$ & $60.4 \pm 4.8$ & $91.0 \pm 2.7$ \\
\hline \multirow{6}{*}{ M. rotata } & $292430^{\mathrm{b}}$ & $76.6 \pm 3.6$ & $63.4 \pm 4.2$ \\
\hline & $495576^{b}$ & $85.9 \pm 3.0$ & $93.4 \pm 2.1$ \\
\hline & 495577 & $95.6 \pm 2.2$ & $94.7 \pm 2.3$ \\
\hline & 495583 & $97.4 \pm 1.8$ & $95.0 \pm 2.8$ \\
\hline & 495586 & $78.9 \pm 3.6$ & $82.0 \pm 3.3$ \\
\hline & 537236 & $96.4 \pm 1.6$ & $98.1 \pm 1.1$ \\
\hline \multirow[t]{6}{*}{ M. rugosa } & 308061 & $67.0 \pm 4.4$ & $76.3 \pm 4.3$ \\
\hline & 442893 & $97.9 \pm 1.4$ & $100.0 \pm 0.0$ \\
\hline & 487363 & $96.5 \pm 2.0$ & $100.0 \pm 0.0$ \\
\hline & 487374 & $96.2 \pm 1.9$ & $99.1 \pm 0.9$ \\
\hline & 487379 & $98.8 \pm 1.2$ & $100.0 \pm 0.0$ \\
\hline & $487382^{b}$ & $89.4 \pm 3.0$ & $67.7 \pm 4.8$ \\
\hline \multirow[t]{2}{*}{ M. sauvagei } & 499152 & $82.9 \pm 3.1$ & $80.1 \pm 3.4$ \\
\hline & 499153 & $89.9 \pm 2.6$ & $87.4 \pm 3.0$ \\
\hline \multirow[t]{4}{*}{ M. scutellata } & 487392 & $99.1 \pm 0.9$ & $97.2 \pm 1.6$ \\
\hline & 487403 & $96.2 \pm 2.6$ & $90.1 \pm 3.5$ \\
\hline & $487409^{b}$ & $91.1 \pm 2.7$ & $83.9 \pm 3.4$ \\
\hline & 516907 & $76.6 \pm 3.8$ & $75.0 \pm 3.8$ \\
\hline M. soleirolii & 537243 & $97.9 \pm 2.1$ & $100.0 \pm 0.0$ \\
\hline M. tenoreana & $499161^{b}$ & $96.8 \pm 1.3$ & $81.5 \pm 3.1$ \\
\hline \multirow[t]{2}{*}{ M. truncatula } & 566886 & $98.8 \pm 1.2$ & $100.0 \pm 0.0$ \\
\hline & 566890 & $99.1 \pm 0.9$ & $100.0 \pm 0.0$ \\
\hline M. turbinata & 566895 & $98.9 \pm 1.1$ & $100.0 \pm 0.0$ \\
\hline Kanza & & $7.6 \pm 2.8$ & $1.1 \pm 1.1$ \\
\hline Saranac & & $37.2 \pm 4.0$ & $61.2 \pm 4.1$ \\
\hline
\end{tabular}

${ }^{a}$ Mean percentage of plants not supporting conidium production \pm standard error.

${ }^{\mathrm{b}}$ The percentage of plants resistant to isolates I7 and I8 differ according to $\mathrm{Z}$ test $(P=0.05)$.
(Table 2) was about twice the expected rate of 15 to $20 \%$ (11).

A greater percentage of plants in approximately $11 \%$ of the medic accessions was more resistant to $\mathrm{I} 7$ than to $\mathrm{I} 8$, and more plants in $2 \%$ of accessions were more resistant to I8 than to I7 (Table 2). Approximately $13 \%$ of alfalfa accessions were more resistant to $\mathrm{I} 7$ than to I8, and another $13 \%$ were more resistant to I8 (9). Isolate-specific resistance in alfalfa was associated with the geographical source of the accession (9), but no such pattern was evident in the medics.

The standard seedling test (11) has proven effective in evaluating and screening for downy mildew resistance in alfalfa. For example, CUF 101, with $28 \%$ of plants resistant to a mixture of isolates I5 and I7 and $2 \%$ of plants resistant to I8, was screened with a mixture of I5 and I7 conidia, and the resistant plants were intercrossed to produce UC 123 (4). Resistance to the I5 and I7 mixture increased to $66 \%$ in UC 123 and remained relatively unchanged at 5\% for I8. Then UC 123 was screened for resistance to only I8 to produce UC 143, in which resistance to I8 was increased to $67 \%$ (4).

The severity of the standard seedling test and the nondescript chlorotic and necrotic leaf spot symptoms with sparse conidial production may explain why downy mildew occurred under these test conditions but has not been observed on medics in nature.

The abundant hypersensitive reactions to inoculations, the generally light conidial production on the most susceptible accessions, and the high proportion of symptomless plants indicate that the medics harbor a wide array of genetic resistance to these isolates of $P$. trifoliorum.

\section{ACKNOWLEDGMENTS}

We thank the personnel at the USDA Western Regional Plant Introduction Station for providing the core collection seed. We thank Duane Brown for his help with the statistics.

\section{LITERATURE CITED}

1. Crawford, E. J., Lake, A. W. H., and Boyce, K. G. 1989. Breeding annual Medicago species for semiarid conditions in southern Australia. Adv. Agron. 42:399-437.

2. Diwan, N., Bauchan, G. R., and McIntosh, M. S. 1994. A core collection for the United States annual Medicago germplasm collection. Crop Sci. 34:279-285.

3. Lamprecht, S. C., and Knox-Davies, P. S. 1984. Preliminary survey of foliage diseases of annual Medicago spp. in South Africa. Phytophylactica 16:177-183.

4. Lehman, W. F., Stuteville, D. L., Nielson, M. W., and Marble, V. L. 1983. Registration of UC 123 and UC 143 alfalfa germplasms. Crop Sci. 23:403.

5. Lesins, K. A., and Lesins, I. 1997. Genus Medicago (Leguminosae). A taxogenetic study. Junk, The Hague, Netherlands.

6. Melchers, L. E., and Patel, M. K. 1929. Study of Peronospora trifoliorum de Bary on species of Leguminosae. Ia. Acad. Sci. 36:113-119.

7. Quiros, C. F., and Bauchan, G. R. 1988. The genus Medicago and the origin of the Medi- 
cago sativa complex. Pages 93-124 in: Alfalfa and Alfalfa Improvement. A. A. Hanson, ed. American Society of Agronomy, Madison, WI.

8. Renfro, B. L., and Sprague, E. W. 1959. Reaction of Medicago species to eight alfalfa pathogens. Agron. J. 51:481-483.

9. Skinner, D. Z., and Stuteville, D. L. 1992. Geographic variation in alfalfa accessions for resistance to two isolates of Peronospora trifoliorum. Crop Sci. 32:1467-1470.

10. Stuteville, D. L. 1990. Downy mildew. Pages 14-15 in: Compendium of Alfalfa Diseases. 2nd ed. D. L. Stuteville and D. E. Erwin, eds. American Phytopathological Society, St. Paul, MN.

11. Stuteville, D. L. 1991. Downy Mildew. Section D-5 in: Standard Tests to Characterize
Alfalfa Cultivars. 3rd ed. C. C. Fox, R. Berberet, F. A. Gray, C. R. Grau, D. L. Jessen, and M. A. Peterson, eds. North American Alfalfa Improvement Conference, Beltsville, MD.

12. Stuteville, D. L., Sorensen, E. L., and Johnson, L. B. 1984. Reaction of eight glandularhaired Medicago species to four alfalfa pathogens. Page 75 in: Rep. Alfalfa Improve. Conf., 29th. 